\title{
Experiências maternas durante a hospitalização do recém-nascido prematuro
}

Maternal experiences during hospitalization of premature newborn

Experiencias maternas durante la hospitalización del recién nacido prematuro

Karolina Carvalho da Silva ${ }^{1}$ (D) https://orcid.org/0000-0001-8062-5067)

Nalú Pereira da Costa Kerber ${ }^{2}$ (D) https://orcid.org/0000-0001-9647-1656)

Cleonara Sousa Gomes e Silva ${ }^{1}$ (D) https://orcid.org/0000-0002-4827-8306)

Marialda Moreira Christoffel ${ }^{3}$ (D) https://orcid.org/0000-0002-4037-8759)

Evanilda Souza de Santana Carvalho ${ }^{1}$ (D) https://orcid.org/0000-0003- 4564-0768)

Silvia da Silva Santos Passos ${ }^{1}$ (D https://orcid.org/0000-0002-2104-5131)

Luciano Marques dos Santos ${ }^{1}$ (D) https://orcid.org/0000-0001-7866-6353)

\section{Resumo}

Objetivo: Compreender a experiência materna diante da hospitalização do recém-nascido prematuro na Unidade de Terapia Intensiva Neonatal.

Métodos: Trata-se de um estudo qualitativo, realizado de maio a junho de 2014 com treze puérperas com prematuros hospitalizados nas unidades neonatais de dois hospitais públicos de Feira de Santana na Bahia. Os dados foram coletados por meio de entrevista gravadas e submetidos a análise de conteúdo.

Resultados: a experiência materna foi marcada por intenso sofrimento, traduzido pelos sentimentos de medo e crenças negativas sobre a prematuridade e 0 uso de tecnologias. Este sofrimento foi superado quando as mães perceberam a recuperação do seu filho, mantendo-as mais próximas dele, além de acreditar no ambiente da unidade neonatal.

Conclusão: É importante que os trabalhadores da saúde incluam as experiências e vivências maternas e familiares para planejar intervenções que possam amenizar o sofrimento inicial e apoia-las durante toda a hospitalização.

\begin{abstract}
Objective: This work aims at understanding the maternal experiences during hospitalization of premature infants in the NICU (Neonatal Intense Care Unit).

Methods: This work was based on qualitative study, done from May to June 2014, with thirteen postpartum women and their premature infants hospitalized in Neonatal units of two public hospitals in Feira de Santana - Bahia. The data were collected through recorded interviews and submitted to analysis of content.

Results: The maternal experience was marked by intense suffering, expressed with feelings of fear and negative beliefs about prematurity and use of technology. This suffering was overcome when the mothers noticed the recovery of their children and could be closer to them, in addition, those mothers became more confident about the Neonatal unit enviroment.

Conclusion: It is important that healthcare workers take into consideration maternal and familial experiences in order to plan interventions that might reduce initial suffering and support postpartum women during hospitalization.
\end{abstract}

\section{Resumen}

Objetivo: Comprender la experiencia materna delante de la hospitalización del recién nacido prematuro en la Unidad de Terapia Intensiva Neonatal.

Métodos: Se trata de unos estudios cualitativos, realizados de mayo hasta junio de 2014 con trece puérperas con prematuros hospitalizados en las unidades neonatales de dos hospitales públicos de Feira de Santana en la Bahia. Los datos fueron recolectados por medio de entrevistas grabadas y sometidos a análisis del contenido. Resultados: La experiencia materna fue marcada por intenso sufrimiento, traducidos por los sentimientos de miedo y creencias negativas sobre la prematuridad y el uso de tecnologías. Este sufrimiento fue superado cuando las madres percibieron la recuperación de su hijo, manteniéndolas más cerca de él; además de creer en el ambiente de la unidad neonatal.

Conclusión: Es importante que los trabajadores de la salud incluyan las experiencias y vivencias maternas y familiares para planear intervenciones que puedan amenizar el sufrimiento inicial y apoyarlas durante toda la hospitalización.

\section{Descritores}

Enfermagem Pediátrica; Recém-nascido prematuro; Unidades de terapia intensiva neonatal; Relações mãe-filho; Enfermagem

\section{Keywords}

Pediatric Nursing; Infant, premature; Intensive care units, neonatal; Motherchild relations; Nursing

\section{Descriptores}

Enfermería Pediátrica; Recien nacido prematuro; Unidades de cuidado intensivo neonatal; Relaciones madrehijo; Enfermería

\section{Como citar:}

Silva KC, Kerber NP, Gomes e Silva CS, Christoffel MM, Carvalho ES, Passos SS, et al. [Maternal experiences during hospitalization of premature newborn]. Rev Soc Bras Enferm Ped. 2019;19(1):7-15. Portuguese

${ }^{1}$ Universidade Estadual de Feira de Santana, Feira de Santana, BA, Brasil.

${ }^{2}$ Universidade Federal do Rio Grande, Rio Grande, RS, Brasil.

${ }^{3}$ Escola de Enfermagem, Universidade de São Paulo, Ribeirão Preto, SP, Brasil.

Conflitos de interesse: nada a declarar.

Submetido: 29 de Março de 2019 | Aceito: 28 de Junho de 2019

Autor correspondente: Cleonara Sousa Gomes e Silva | E-mail: cleosilvauefs@gmail.com

DOI: http://dx.doi.org/10.31508/1676-3793201900002 


\section{Introdução}

A prematuridade é definida de acordo com a avaliação da idade gestacional (IG), e considera-se parto prematuro quando a criança nasce antes das 36 semanas e seis dias. ${ }^{(1)}$

A Organização Mundial da Saúde (OMS) no Relatório Born Too Soon, declarou que ações urgentes são necessárias para enfrentar os estimados 15 milhões de recém-nascidos prematuros que nascem em todo o mundo, principalmente porque as taxas deste tipo de parto aumentam a cada ano. O Brasil ocupa a $10^{\mathrm{a}}$ posição entre os países responsáveis por $60 \%$ dos nascimentos prematuros do mundo, com a estimativa de que ocorreram 250 mil ou mais no ano de 2010.(2)

Por sua vez, a maioria dos recém-nascidos prematuros (RNPT) necessitam de hospitalização em Unidades de Terapia Intensiva Neonatal (UTIN) ${ }^{(3)}$ ou semi-intensiva para receber suporte respiratório, hemodinâmico, nutricional, metabólico e hidroeletrolítico, o que muito contribuirá para a recuperação clínica.

Entretanto, a internação do prematuro na UTIN causa forte impacto familiar contrastando com o que foi idealizado na gravidez, principalmente pela mãe. Estas podem apresentar sentimentos como culpa, medo, estranhamento ao ver o filho pela primeira vez, angustia, tristeza e ansiedade. Podem, também, mostrar-se com dificuldades para desenvolver o papel de mãe, manifestando-se sensações de baixa autoestima, inferioridade e vazio, o que pode ser influenciado pelos equipamentos e tecnologias duras utilizadas para auxiliar na maturação dos sistemas orgânico do recém-nascido, as quais impedem, temporariamente, o contato entre mãe e filho. ${ }^{(4)}$

Durante toda a hospitalização do RNPT, as mães necessitam ser preparadas para reduzir expectativas que venham a dificultar a adaptação da família, ${ }^{(5)}$ pois, além da experiência de tornarem-se mães em um contexto adverso, terão que enfrentar seus medos e fortalecer-se para auxiliar o prematuro. ${ }^{(4)}$

A relevância deste trabalho consistiu em contribuir para reflexão sobre a experiência das puérperas e famílias, auxiliando-os a amenizar as adversidades advindas da condição de hospitalização do recém-nascido prematuro na UTIN.

Direcionar a investigação para a experiência materna justificou-se por ser a hospitalização de RNPT em UTIN um processo complexo que envolve a frustração de planos e expectativas de familiares. Ao observar durante as práticas assistenciais que, além das mães, poucos familiares participavam do processo de hospitalização do prematuro, sendo a figura materna o principal membro familiar a acompanhá-lo, desse modo, surgiu a seguinte questão: “Como se dá a experiência materna diante da hospitalização do RNPT na UTIN?" traçou-se como objetivo deste estudo compreender a experiência materna diante da hospitalização do RNPT na UTIN.

\section{Métodos}

Estudo do tipo qualitativo, descritivo e exploratório. Realizado nas unidades de alojamento conjunto e materno infantil de dois hospitais púbicos da cidade de Feira de Santana na Bahia, no período de maio a junho de 2014.

Participaram treze puérperas com recém-nascidos prematuros hospitalizados na UTIN. Foram utilizados como critérios de inclusão: ser primigesta mãe de RNPT hospitalizado na UTIN por mais de 48 horas; sem experiência de hospitalização de membro familiar em ambiente de terapia intensiva; estar clinicamente estável e com condição de se comunicar durante as entrevistas. Foram excluídas: mulheres com intercorrências clínicas (hemorragias, infecção, complicação cirúrgica, depressão puerperal); puérperas com RNPT que apresentou malformações congênitas e aquelas que já haviam recebido alta hospitalar e não permaneciam 24 horas nos hospitais em estudo. Utilizou-se a saturação teórica dos dados como critério para a finalização das entrevistas qualitativas.

Os dados empíricos foram coletados através de entrevistas semiestruturadas, conduzidas com apoio de um roteiro que continha dados sociodemográficos e gestacionais, além da seguinte questão norteadora: como está sendo para a senhora a experiência ter um filho prematuro hospitalizado na UTIN? Para capturar as falas das entrevistadas utilizou-se um aparelho MP4 de forma a não perder nenhum dado e poder conversar livremente com a puérpera.

As entrevistas, únicas para cada puérpera e que duravam em média 15 minutos, foram realizadas no conforto de enfermagem das unidades estudadas, sen- 
do transcritas na íntegra e submetidas a correções ortográficas, mantendo-se suas ideias centrais.

Para análise dos dados, utilizou-se o referencial conceitual do Modelo de Sofrimento, que se baseou nas discussões referentes ao sofrimento e à tolerância. A tolerância caracteriza-se como a decisão do indivíduo em aceitar a situação vivenciada, enquanto que o sofrimento é uma manifestação emocional mediante ao que ocorre no presente momento, do que foi modificado e na antecipação do que pode acontecer. ${ }^{(6,7)}$

Assim, as entrevistas, como material que constituiu o corpus empírico do estudo, foi submetido à análise de conteúdo, ${ }^{(8)}$ conforme os conceitos do Modelo de Sofrimento, sendo realizado pelo pesquisador o agrupamento dos dados por temas e examina os casos no estudo para certificar-se de que todos os achados de cada tema foram incluídos e comparados. ${ }^{(9)}$

Após leituras superficiais e mais aprofundadas emergiram três categorias e oito subcategorias, sendo elas: Vivendo dias difíceis no início da experiência e as subcategorias, Sentindo-se triste, tendo medo do prematuro não sobreviver, pensando no sofrimento do RN causado pelos procedimentos e aparelhos e sofrendo diante da vulnerabilidade do prematuro; Tolerando a hospitalização diante da recuperação clínica do prematuro e as subcategorias: percebendo que o prematuro está sobrevivendo, ficando mais próximo do filho; sofrendo com o tempo e tendo esperança e as subcategorias, sentindo-se sozinha e tendo preocupações e incertezas. Neste artigo, foram apresentados os trechos mais relevantes de cada subcategoria.

Este estudo atendeu aos princípios éticos que envolvem as pesquisas com seres humanos descritos na Resolução no 466/2012 do Conselho Nacional de Saúde. Foi devidamente aprovado pelo Comitê de Ética em Pesquisa da Universidade Estadual de Feira de Santana sob o Parecer 643.668.

As entrevistadas receberam informações sobre o objetivo, metodologia, riscos, benefícios e participação voluntária no estudo, através da leitura e assinatura, em duas vias, do Termo de Consentimento Livre e Esclarecido (TCLE), sendo que nenhuma das convidadas desistiu da participação na pesquisa, nem desejou suprimir ou acrescentar algo em sua entrevista. Para garantir o anonimato das entrevistadas foram utilizados os códigos "E01 a E13", nos quais a letra representou o nome entrevistada e o número a ordem de realização da entrevista.

\section{Resultados}

O estudo foi realizado com treze participantes, dessas, seis foram realizadas no Hospital Geral Clériston Andrade (HGCA) e sete no Hospital Inácia Pinto dos Santos (HIPS). Com relação à idade, seis mulheres tinham de 20 - 30 anos, quatro tinham $\leq 19$ anos e três delas tinham entre 31-41 anos. Dentre as participantes, 12 se autodeclararam pardas ou negras e apenas uma branca. Predominou o estado civil casado, com seis mulheres, seguidas por cinco em união estável e duas solteiras. Das 13 entrevistadas, todas possuíam de seis a onze anos de estudo. Com relação ao município de residência, Feira de Santana predomina, com oito das puérperas.

Diante da hospitalização do RNPT na UTIN a experiência das puérperas participantes deste estudo, pode ser compreendida a partir das três categorias e oito subcategorias, que emergiram do material empírico.

\section{Vivendo dias difíceis no início da experiência}

O início da experiência materna na UTIN foi marcado por dias difíceis caracterizados pelos diversos sentimentos vivenciados, relacionados à tristeza, a crença da possibilidade de não sobrevivência do prematuro, medo dos aparelhos utilizados no suporte terapêutico do filho, a solidão, preocupações e incertezas quanto ao futuro.

\section{Sentindo-se triste}

Ao saber que o filho estava na UTIN e, ao entrar nesta unidade hospitalar nos primeiros dias da experiência, a puérpera vivenciou o sentimento de tristeza. Esse sentimento decorreu da impossibilidade de cuidar de seu filho como gostaria e de levá-lo para casa após o parto, pois, na UTIN, ela não teria controle sobre a situação. Assim, nas falas as puérperas emergiu-se o sentimento de incapaz de ajudar o filho hospitalizado ou mesmo de tocá-lo, diante de sua gravidade clínica e da demanda de cuidados complexos, vendo-se impotente para contribuir com a melhora do estado do RN e dando início a um período de intenso sofrimento, conforme descrito nos relatos a seguir: 
Quando vi minha filha na UTIN senti tristeza e me achei incapaz de ajudá-la. (E04)

Quando ele foi para a UTIN eu senti muita tristeza. [...] dá uma tristeza porque não pode pegar. Não pode levar logo para casa. (E08)

Quando eu soube que meu filho ia para UTIN fiquei triste [...] A experiência do meu filho na UTIN está sendo sofrida [...] eu não sei te dizer como é este sofrimento, mas eu só sei que este sendo ruim. Eu chorei e tudo. (E11)

\section{Tendo medo do prematuro não sobreviver}

O sofrimento inicial da experiência da puérpera acarretou na constante preocupação com a sobrevivência do prematuro, sendo essa uma situação muito difícil. Para as entrevistadas, a hospitalização na unidade de cuidados intensivos acontece devido às condições clínicas graves do RNPT, tendo assim, maior probabilidade de morte do que sobrevivência, o que as mobilizou no sentido da vivência de intensa preocupação diária, marcada pelo choro constante, como identificado nas falas:

[...] o medo é de o bebê não sobreviver [...] porque nós temos que passar por tudo isso. O sofrimento e a cada dia uma notícia diferente [...]. (E03)

[...] eu só fazia chorar, porque para mim iria morrer. Para mim estava na UTIN porque estava em estado gravíssimo [...]. (E06)

[...] quando o bebê vai para UTIN é porque geralmente não está muito bem. Então, eu ficava imaginando porque tem criança que vai para UTIN passa uma semana e falece, por isso eu ficava só imaginando essas coisas, dele ter ido para a UTIN e falecer lá. (E08)

\section{Pensando no sofrimento do RN causado pelos procedimentos e aparelhos}

A separação do filho, por ter que deixá-lo na UTIN, em um cenário cheio de aparatos tecnológicos e dispositivos para auxílio na manutenção da vida e repleto de procedimentos invasivos, contribuiu para aumentar o sofrimento da puérpera durante os dias de hospitalização. Presenciar a realização de procedimentos, a exemplo da administração de medicamentos, ou visualizar os aparelhos utilizados na UTIN como suportes tecnológicos de apoio à terapêutica do prematuro, principalmente, o relacionado à respiração/ventilação pulmonar, tornaram as puérperas apreensiva com o estado do recém-nascido e com sentimento de impotência.

Um sofrimento para o bebê, porque tem que tomar medicação, ter que ir para UTIN [...] tanta medicação, tanto remédio, tanta injeção. [...] Eu acho que ele é tão pequenininho [...] ter que fazer passar por tudo isso, com tanta coisa. (E03)

[...] ruim porque eu o vi todo intubado [...]. (E05)

[...] quando você zêe com aquelas coisas para respirar, cheia de coisa, você entra em pânico. (E06)

[...] mas também é muito triste ver o filho todo cheio de fios e receber aquele monte de medicamento (referindo aos infundidos de forma contínua em bomba de infusão). (E07)

Este medo decorre da crença de que a utilização destes recursos estava relacionada ao agravamento da condição clínica do prematuro, potencializando, assim, uma experiência muito dolorosa e de sofrimento para o filho, o que a faz sentir-se ainda mais triste.

\section{Sofrendo diante da vulnerabilidade do prematuro}

Para elas, o filho prematuro e hospitalizado era um ser frágil, pequeno, indefeso e que estava exposto ao ambiente agressivo da UTIN, podendo ao longo do tempo adquirir infecções ou doenças, mediante sua imaturidade orgânica. As entrevistadas entenderam o significado da prematuridade, ao relatarem que o ambiente uterino era um espaço mais seguro para o desenvolvimento do prematuro, e assim seria uma forma de protegê-lo das adversidades encontradas no ambiente do cuidado intensivo.

$\mathrm{Na}$ percepção delas, a UTIN seria um espaço ameaçador para a relação entre mãe e filho, pois a incubadora foi para elas uma barreira inicial para o contato com o prematuro, que as levaram a pensar na impossibilidade de tocá-lo a fim de protegê-lo, temendo provocar algum problema nele. Assim, perceber que o filho prematuro era um ser muito vulnerável, diante de sua imaturidade orgânica, potencializa ainda mais o sofrimento vivenciado, como expressado nas falas a seguir:

Ah, uma vontade de chorar, ver ela se mexendo, uma criança tão pequeninha, tão frágil. Nós carregamos a criança dentro da barriga, protege de toda maneira que pode e quando vê lá tão quietinha, dentro da UTIN ali, e sem poder pegar direito, toda guardadinha dentro daquele vidro. (E08) 
[...] no início eu pensava que qualquer coisinha iria quebra-la. Às vezes é, mas temos que aprender, porque a gente vai conviver assim para o resto da vida com ele. Porque vai crescer, mas continua sendo um bebê prematuro, mais fácil de pegar infecção, mais fácil de pegar doença e tal [...] mas ficamos meio assim com medo de pegar e tal porque é muito pequenininho [...]. (E10)

Decorrente disso, a puérpera sentia medo de tocar em seu bebê por receio de interferir no funcionamento dos aparelhos e dispositivos, pensando que algo ruim poderia acontecer durante a manipulação do RN. Entretanto, as participantes deste estudo reconheceram que os equipamentos e procedimentos utilizados foram necessários para manter a vida de seu filho prematuro.

\section{Tolerando a hospitalização diante da recuperação clínica do prematuro}

A vivência de sofrimento inicial e os desequilíbrios afetivos e cognitivos da puérpera foram superados ao perceber que o filho estava tendo uma boa maturação dos órgãos e sobrevivendo à situação de hospitalização na UTIN. Isso a faz perceber a necessidade de estar mais próxima do prematuro e a acreditar que esta unidade e as pessoas que lá trabalham eram importantes para um bom desfecho da experiência.

Neste sentido, a experiência da puérpera tem seu curso alterado através de um período agora marcado pela estabilidade emocional, traduzido pela vivência de um estado de tolerância da situação de estresse.

\section{Percebendo que o prematuro está sobrevivendo}

Superada a crise e o sofrimento inicial, os sentimentos maternos tenderam a mudar, após alguns dias de hospitalização do RNPT na UTIN, especialmente, quando as puérperas constataram a evolução clínica do filho. Elas se tornaram mais calmas ao longo da experiência.

[...] mas depois que passa o terceiro dia, quarto dia, você já se acalma. Difícil mesmo são os primeiros dias. (E06)

É ótimo ver o bebê lá. (E07)

Quando eu vi na UTI senti emoção [...] assim, dá uma emoção por saber que está vivo, está bem. (E08)

Foi uma sensação boa [...] porque eu o vi melhor [...]. (E05)
Apesar de vivenciarem muitos sentimentos negativos inicialmente, ainda sobrevive nessas mulheres sentimentos que as mantêm fortalecidas e confiantes quanto à recuperação do filho, o que as mobilizou no sentido de tolerar a experiência.

\section{Ficando mais próximo do filho}

Após constatar que o filho estava vencendo os desafios impostos pela sua prematuridade e lutava para sobreviver, as puérperas buscam estar mais próxima dele, acompanhando-o de perto na UTIN. Assim, ter a possibilidade de acesso livre ao espaço do cuidado intensivo neonatal, de tocá-lo diariamente e vê suas reações de perto, mobilizou a puérpera a continuar firme diante da experiência vivenciada, superando a tristeza que pouco a pouco foi substituída por esperança e alegria.

Foi uma sensação boa e ruim ao mesmo tempo. Boa porque eu o vi. Peguei na mãozinha dele e ele apertou. (E05)

[...] agora nas outras vezes, eu vi que estava reagindo. Já está tomando leite normal. (E07)

[...] eu estou perto. Toda hora venho vê-lo. Eu me sinto mais alegre porque posso vê-lo quando eu quero. (E13)

Ao longo da hospitalização, à medida que a puérpera foi envolvida nos cuidados com o filho, possibilitou para ela acreditar que o mesmo estava se recuperando, tornando-a mais alegre, confiante e aliviada diante da situação. Esses cuidados, por menos complexos que foram, representaram para elas a possibilidade de colaborar com o desenvolvimento do prematuro.

Ah, bem melhor, ontem mesmo eu já pude pegar ela no colo. Já foi muito bom, saber que está bem e pegar pela primeira vez. Eu tenho certeza que ela está se recuperando e vai se recuperar rápido para gente ir logo para casa. (E08)

A experiência está sendo ótima, que eu posso ir lá, posso pegar ela no colo, posso trocar fralda, dar beijo, posso ver a hora que eu quiser. Está sendo ótimo. (E01)

E agora eu me sinto bem, feliz, que posso ficar com ele o tempo todo. Meu filho agora é minha vida. Não tenho nada a reclamar mais. (E09)

A participação nos cuidados promoveu o fortalecimento do vinculo entre mãe e filho e ajuda a mãe a superar os medos e sentimentos negativos comuns ao processo inicial de hospitalização do RNPT na UTIN. 


\section{Sofrendo com o tempo e tendo esperança}

Após o período de estabilidade emocional e de acreditar que tudo seria bem resolvido, a puérpera vivencia outros momentos de sofrimento, mesmo sabendo que o filho estava se recuperando. Ela entrou nesta nova etapa da experiência de ter um filho prematuro na UTIN flutuando entre períodos de tolerância à situação e de sofrimento, tendo solidão e vivenciando novas incertezas em relação ao futuro do filho ainda na UTIN. Mesmo assim, ela acreditou que esta unidade hospitalar foi o melhor lugar para o filho.

\section{Sentindo-se sozinha}

A experiência da puérpera não foi considerada por elas como agradável, pois, diante do sofrimento vivenciado e por estar afastada de seu núcleo familiar, a mesma se sentia desamparada e sozinha na situação. Como descrito nas falas a seguir:

A experiência não está sendo muito boa, porque eu me sinto só às vezes [...] eu só quero que seja bem rápido. Eu quero sair daqui, porque não gosto de ficar aqui no hospital.

[...] eu estou achando angustiante, porque eu queria estar em casa. (E05)

Vivenciar sozinha a experiência de hospitalização do prematuro na UTIN representa para a puérpera um momento angustiante e sem suporte constante da família no hospital, o que a faz desejar que o momento vivenciado seja breve e que logo ela possa retornar para seu núcleo familiar, tendo que se adaptar rapidamente a esse momento.

\section{Tendo preocupações e incertezas}

Diante da experiência ao adaptar-se ao cenário da UTIN, a puérpera tentou retomar o controle da situação buscando informações constantes com os trabalhadores da saúde sobre a evolução clínica do prematuro. Essa tomada de decisão faz a puérpera vivenciar novas preocupação e incertezas.

Estes sentimentos decorreram da necessidade de saber sobre a condição clínica do filho, de suas reações ao tratamento oferecido na UTIN e se o tempo prolongado de hospitalização poderia refletir negativamente na sua evolução, temendo assim, que algo de ruim aconteça novamente na experiência com destaque para a morte de seu filho prematuro. Assim, notou-se que ela percebe uma ameaça potencial para seu retorno para casa com o filho.

Assim, porque a pessoa já vai querendo saber como está. Se aconteceu alguma coisa. Se está reagindo bem. (E07)

[...] não está sendo muito boa. Eu me sinto nervosa, porque meu bebê está passando muitos dias aqui. Fica parecendo que ele não está melhorando e nunca é bom ficar no hospital, não é? Fico preocupada de tudo dar errado e meu filho piorar. (E13)

Ao observar o prolongamento do tempo de hospitalização do filho, as participantes voltaram a experimentar sentimentos de tensão e as deixaram em constante alerta.

\section{Discussão}

O nascimento prematuro é um evento que provoca a separação brusca entre mãe e filho imediatamente após o parto, ${ }^{(10,11)}$ devido à condição de risco iminente de complicações, instabilidade clínica do recém-nascido, ${ }^{(11)}$ necessitando-se de hospitalização na UTIN, o que leva à puérpera a vivenciar intenso sofrimento.

Ao deparar-se com a necessidade da hospitalização em UTIN do recém-nascido, os pais se sentiram incompletos por não poder realizar o seu papel, manifestaram medo da morte de seu filho, sensação de distanciar-se da realidade antes vivida, além de sentimentos antagônicos de segurança e alegria. ${ }^{(12)}$

No presente estudo os sentimentos mais relatados foram a tristeza, impotência e medo da morte, todos estes notados no início da hospitalização, que tenderam a ser substituídos por sentimento de satisfação e alegria ao perceber o desenvolvimento do filho, voltando a serem vistos os sentimentos negativos com a constatação da extensão temporal da hospitalização.

A perturbação do equilíbrio emocional e cognitivo da puérpera e os sentimentos vividos na experiência de ver seu filho na UTIN estavam associados ao choque de ingressar nessa unidade de $\operatorname{cuidados}^{(13)} \mathrm{e}$ perceber sua dinâmica de funcionamento, dispositivos de apoio à vida, utilizados para assegurar a sobrevida do prematuro e procedimentos complexos. ${ }^{(11,14)}$

Assim, o desequilíbrio emocional e cognitivo apareceram na experiência das puérperas pela ruptura 
do cotidiano de forma inesperada e da necessidade da hospitalização de seu filho em uma unidade representada como um ambiente complexo, destinado a pacientes graves. Deparar-se com o filho muito pequeno, afastado por um aparato tecnológico a fez percebê-lo frágil, indefeso e exposto às adversidades do ambiente do cuidado intensivo neonatal com a utilização de tecnologias e procedimentos invasivos.

Tais sentimentos, também decorreram da necessidade que o prematuro possui de receber cuidados profissionais ininterruptos ${ }^{(10)}$ incertezas quanto à doença $\mathrm{e}$ ao tratamento, e por temer a possibilidade de perder o seu filho. ${ }^{(11)}$

Por isso, a puérpera vivenciou o sentimento de impotência diante de uma situação sobre a qual ela acredita não poder fazer nada no início da experiência, por ainda não possuir recursos internos e externos capazes de ajudá-la no enfrentamento da situação. Estes sentimentos repercutem negativamente na experiência materna, levando a intenso sofrimento e a adiar o contato direto com o filho prematuro.

Neste momento da experiência vivenciada, notou-se que as puérperas entrevistadas estavam em plena vulnerabilidade diante da situação de doença e hospitalização de um filho, por sentir-se ameaçada em sua autonomia, sob pressão das condições de saúde. Os elementos desencadeadores desse sentimento podem ter sido o despreparo para agir, já que todas as entrevistadas estavam vivendo a experiência aqui discutida pela primeira vez..$^{(15)}$

$\mathrm{Na}$ presente pesquisa, pode-se observar alguns atributos definidores da vulnerabilidade da família, relacionados tanto com o contexto da prematuridade e família. Quanto a prematuridade, destacaram-se as incertezas, impotência, ameaça real ou imaginária, exposição ao dano, temor do resultado, submissão ao desconhecido e expectativas de retornar à vida anterior. No contexto da família, as falas demonstraram desequilíbrio em sua capacidade de funcionamento no início da experiência, distanciamento, alteração na vida familiar e conflitos familiares, encontrando esses resultados em outro estudo. ${ }^{(15)}$

Como consequência da vulnerabilidade, os familiares alternaram momentos em que pensavam não conseguir fazer nada, com outros em que tentaram resgatar sua autonomia participando dos cuidados ao filho. ${ }^{(15)}$
Além disso, na experiência materna, as barreiras estruturais, tais como a utilização de incubadoras, aparelhos para o suporte respiratório e monitorização contínua de sinais vitais, tiveram implicações negativas no que se refere ao estabelecimento de contatos iniciais e vínculo com o prematuro.

O sofrimento da puérpera também foi observado, neste estudo, diante dos relatos de solidão, afastamento de seu núcleo familiar e ausência de suporte físico e emocional durante os primeiros dias de hospitalização do prematuro na UTIN. Por isso, a puérpera enfrenta sozinha todas as demandas decorrentes do processo de hospitalização, que aliado à ausência de recursos para o enfrentamento dessa experiência tem o seu sofrimento ainda mais intensificado.

Após familiarizar-se com o ambiente da UTIN, a impressão inicial foi superada; contudo, o delineamento desta experiência materna traz à tona o sofrimento psicológico desencadeado pela internação do filho. ${ }^{(16)}$

Com o tempo, a estabilidade clínica do prematuro e a entrada diária da mãe na UTIN para acompanhá-lo de perto, amenizou o sofrimento materno, deixando-a mais fortalecida e confiante para enfrentar a situação. Nesse novo momento da experiência, a puérpera experimenta a alegria e constata que o filho está vivo e com possibilidades de sobrevivência diante dos recursos tecnológicos e dos profissionais que compõe a UTIN. ${ }^{(17)}$

Assim, a puérpera enfrentaram as barreiras iniciais que a impediram do contato direto com o prematuro e passa a reconhecer a necessidade de estar mais próxima dele e no ambiente da UTIN.

Essa aproximação pôde possibilitar à puérpera a transmitir amor e carinho para o filho prematuro, e um contato maior com o mesmo, sendo possível até oferecer cuidado e adaptar-se as condições do recém-nascido, desse modo, as mães sentiram-se mais alegres. ${ }^{(17)}$

Por isso, a permanência integral da puérpera e sua vivência no ambiente da UTIN tornou-se estratégia primordial para a mudança das representações negativas sobre esta unidade de cuidado, levando-a a acreditar que ela é imprescindível para a recuperação clínica do prematuro. ${ }^{(14)}$

Nessa etapa, conhecer a condição de saúde do prematuro e a necessidade do mesmo em receber cuidados especiais para assegurar a sua sobrevivência, proporcionou à puérpera uma nova crença de que a UTIN foi o ambiente ideal para o seu tratamento. ${ }^{(18)}$ 
Embora a UTIN seja um ambiente inóspito, pouco acolhedor e ligado à iminência de morte, a puérpera ao presenciar a dinâmica do setor e o trabalho da equipe, percebeu que se trata de um ambiente terapêutico, destinado à recuperação de seu filho. Essa compreensão a tranquilizou e reforçou ainda mais a confiança nos cuidados prestados pela equipe. ${ }^{(19)}$

Além disso, percebeu-se a importância da rede de apoio familiar para o enfrentamento de tal situação, esse recuso auxiliam as mulheres a se sentirem mais alegre e confiante. As puérperas ao serem questionadas sobre o apoio familiar, respondem com entusiasmos e ênfase sobre a importância do acompanhamento dos esposos, familares e amigos. ${ }^{(20)}$

Viu-se a necessidade de os profissionais de saúde desenvolverem habilidades para identificar nas puérperas a ocorrência de problema de ordem cognitiva, afetiva e comportamental durante a hospitalização do prematuro na UTIN. Também, é imprescindível que esses avaliem a estrutura familiar e as demandas de cuidados dessa mulher, incorporando na sua prática clínica diária a filosofia do cuidado centrado na família.

\section{Conclusão}

O processo de hospitalização do prematuro na UTIN demonstrou, inicialmente, ser uma experiência muito difícil que leva a mãe a vivenciar o medo da hospitalização no ambiente de cuidados complexos, cujos aparelhos e dispositivos de suporte à vida utilizados no cuidado ao prematuro são na concepção materna causadores de intenso e contínuo sofrimento ao filho. No entanto, ao ver a recuperação clínica do prematuro, a puérpera sentiu-se mais confiante e aliviada pensando que a situação estava próxima do fim, e ela iria para casa com seu filho, como fora planejado. Também, a puérpera passa a depositar total confiança nos trabalhadores do cuidado intensivo neonatal e na própria estrutura da UTIN. A experiência das puérperas foi marcada pelo sofrimento, sendo fundamental que os trabalhadores da saúde considerem suas narrativas sobre a experiência de doença e hospitalização do prematuro, incluindo também as perspectivas de sua família, para assim planejar intervenções que possam amenizar este sentimento e suas implicações ao longo da vivência na unidade. Ainda, é necessário que os trabalhadores da saúde envolvidos nos cuidados intensivos aos neonatais prematuros conheçam a rede de apoio e o suporte social de suas famílias com o objetivo de acioná-los no início da experiência materna e incluí-los no cuidado, buscando reduzir a sobrecarga das puérperas e promover o conforto psicoemocional para elas. Sabendo disto, torna-se primordial a utilização dos fundamentos da filosofia do cuidado centrado na família, considerando-a como uma constante na vida do prematuro e sua principal fonte de cuidados, para assim, criar espaços hospitalares que proporcionem a escuta ativa das demandas da família (como a instituição de grupos de apoio), e considerá-la como uma unidade básica que precisa de cuidados durante a hospitalização do prematuro na UTIN. Torna-se necessário enfatizar que este estudo possui limitação, em relação ao número de participantes em comparação ao grande número de puérperas que vivenciam a hospitalização de um recém-nascido prematuro. Esse fato impossibilita a generalização de seus resultados, contudo o seu valor deve ser considerado ainda que circunscrito à quantidade aplicada. Ressalta-se, também, a importância de novas pesquisas nesse campo, especialmente com relação às experiências de outros membros da família com o nascimento de um recém-nascido prematuro.

\section{Agradecimentos}

Ao projeto multicêntrico intitulado "Parto prematuro: estudos dos fatores associados para construção de estratégias de prevenção" (parecer de número 134/2013) da Universidade Federal do Rio Grande e ao Programa Institucional de Bolsas de Iniciação Científica (PIBIC) da Universidade Estadual de Feira de Santana.

\section{Contribuições}

Silva KC, Kerber NPC, Silva CSG, Christoffel MM, Carvalho ESS, Passos SSS e Santos LM declaram que contribuíram com a concepção do estudo, análise e interpretação dos dados, redação do artigo, revisão crítica relevante do conteúdo intelectual e aprovação da versão final a ser publicada. 


\section{Referências}

1. Reis AT. Prematuridade. In: Araujo LA, Reis AT. Enfermagem na prática materno neonatal. Rio de Janeiro: Guanabara Koong; 2012.

2. World Health Organization. Born too soon: the global action report on preterm birth. Geneva: WHO; 2012.

3. Lima SS, Silva SM, Avila PE, Nicolau MV, Neves PF. Aspectos clínicos de recém-nascidos admitidos em Unidade de Terapia Intensiva de hospital de referência da região norte do Brasil. ABCS Health Sci. 2015;40(2):62-68.

4. Baseggio DB, Dias MP, Brusque SR, Donelli TM, Mendes P. Vivências de mães e bebês prematuros. Temas em Psicologia. 2017;25(1):153-67.

5. Carvalho LS, Pereira CM. As reações psicológicas dos pais frente à hospitalização do bebê prematuro na UTI neonatal. Rev SBPH. 2017;20(2):101-22.

6. Morse JM, Carter B. The essence of enduring and the expression of suffering: the reformulation of self. Sch Inq Nurs Pract. 1996;10(1):43-60.

7. Vasques RC, Bousso RS, Mendes-Castillo AM. A experiência de sofrimento: histórias narradas pela criança hospitalizada. Rev Esc Enferm USP. 2020;45(1):122-129.

8. Bardin L. Análise de conteúdo. Lisboa: Edições 70; 2011.

9. Pope C, Ziebland S, Mays N. Analisando dados qualitativos. In: Pope C, Ziebland S, Mays N. Pesquisa qualitativa na atenção à saúde. Porto Alegre: Artmed; 2009.

10. Veronez M, Borghesan NA, Correa DA, Higarashi IH. Vivência de mães de bebês prematuros do nascimento a alta: notas de diários de campo. Rev Gaúcha Enferm. 2017;38(2):e60911.
11. Medina IM, Granero-Molina J, Fernández-Sola C, Hernández-Padilla JM,Ávila MC, Rodríguez MML. Bonding in neonatal intensive care units: experiences of extremely preterm infants' mothers. Women Birth. 2018;31(4):325-30.

12. Hagen HI, Iversen VC, Svindseth MF. Differences and similarities between mothers and fathers of premature children a qualitative study of parents' coping experiences in a neonatal intensive care unit. BMC Pediatrics. 2016;16(170):1-8.

13. Treherne SC, Feeley N, Charbonneau L,Axelin A. Parents' perspectives of closeness and separation with their preterm infants in the NICU. J Obstet Gynecol Neonatal Nurs. 2017;46(5)737-47.

14. Santos LM, Oliveira IL, Santana RCB, Oliveira VM, Goes ES. Vivências de mães de recém-nascidos prematuros na unidade de terapia intensiva neonatal. Rev Soc Bras Enferm Ped. 2013;13(2):73-81.

15. Mandetta MA, Angelo M. Vulnerabilidade da família: desenvolvimento do conceito. Rev Lat Am Enfermagem. 2005;13(6):982-8.

16. Schmidt KT, Sassá AH, Veronez M, Higarashi IH, Marcon SS. A primeira visita ao filho internado na unidade de terapia intensiva neonatal: percepção dos pais. Esc Anna Nery. 2012;16(1):73- 81.

17. Flacking R, Thomson G, Axelin A. Pathways to emotional closeness in neonatal units - a cross-national qualitative study. BMC Pregnancy and Childbirth. 2016;16:170.

18. Melo RA, Araújo AK, Bezerra CS, Santos NM, Marques WF, Fernandes FE. Sentimentos de mães de recém-nascidos internados em uma unidade de terapia intensiva neonatal. Id on Line Rev Psic. 2016;10(32):1-16.

19. Rocha LL, Dittz ES, Duarte ED, Costa PR. A experiência da puérpera hospitalizada com 0 recém-nascido na unidade de terapia intensiva neonatal. Rev RECOM. 2018;8:e2589.

20. Almeida CR, Morais AC, Lima KD, Silva AC. Cotidiano de mães acompanhantes na unidade de terapia intensiva neonatal. Rev Enferm UFPE. 2018;12(7):1949-56. 